\title{
High-dose amikacin for achieving serum target levels in critically ill elderly patients
}

This article was published in the following Dove Press journal: Infection and Drug Resistance

\author{
Kourosh Sadeghi' \\ Hadi Hamishehkar ${ }^{2}$ \\ Farhad Najmeddin' \\ Arezoo Ahmadi $^{3}$ \\ Ebrahim Hazrati ${ }^{4}$ \\ Hooshyar Honarmand' \\ Mojtaba Mojtahedzadeh ${ }^{1,5}$ \\ 'Department of Clinical Pharmacy, \\ School of Pharmacy, Tehran University \\ of Medical Sciences, Tehran, Iran; \\ ${ }^{2}$ Department of Clinical Pharmacy, \\ Drug Applied Research Center, Tabriz \\ University of Medical Sciences, Tabriz, \\ Iran; ${ }^{3}$ Department of Anesthesia and \\ Intensive Care, Sina Hospital, Tehran \\ University of Medical Science, Tehran, \\ Iran; ${ }^{4}$ Department of Anesthesia and \\ Intensive Care, Imam Reza Hospital, \\ Army University of Medical Sciences, \\ Tehran, Iran; ${ }^{5}$ Pharmaceutical Sciences \\ Research Center, School of Pharmacy, \\ Tehran University of Medical Sciences, \\ Tehran, Iran
}

Correspondence: Mojtaba Mojtahedzadeh Department of Clinical Pharmacy, School of Pharmacy, Tehran University of Medical Sciences, 16 Azar Street,Tehran $|4| 76|44| \mid$, Iran

Tel +989121056031

$\mathrm{Fax}+982166954709$

Email mojtahed@sina.tums.ac.ir
Introduction: To achieve target concentrations, the application of higher-than-standard doses of amikacin is proposed for the treatment of sepsis due to an increase in volume of distribution and clearance, but little data are available on aminoglycoside administration in critically ill elderly patients.

Patients and methods: Forty critically ill elderly patients (aged over 65 years) who required amikacin therapy due to severe documented, or suspected gram-negative infections, were randomly assigned to two treatment groups. Group A (20 patients) received $15 \mathrm{mg} / \mathrm{kg}$ amikacin and Group B (20 patients) received $25 \mathrm{mg} / \mathrm{kg}$ amikacin per day as a single daily dose. All the patients were monitored for renal damage by the daily monitoring of serum creatinine. The amikacin peak $\left(\mathrm{C}_{\max }\right)$ and trough $\left(\mathrm{C}_{\min }\right)$ serum concentrations were measured on Days 3 and 7 postadministration. Results: Data from 18 patients in Group A and 15 patients in Group B were finally analyzed. On Day 3, the amikacin mean $\mathrm{C}_{\max }$ levels in the standard and high-dose treatment groups were $30.4 \pm 11$ and $52.3 \pm 16.1 \mu \mathrm{g} / \mathrm{mL}(P<0.001)$, and the $\mathrm{C}_{\min }$ levels were $3.2 \pm 2.1$ and $5.2 \pm 2.8 \mu \mathrm{g} / \mathrm{mL}$, respectively $(P=0.035)$. On Day 7 , the $\mathrm{C}_{\max }$ levels in the standard and high-dose groups were $33 \pm 7.3$ and $60.0 \pm 17.6 \mu \mathrm{g} / \mathrm{mL}(P=0.001)$, and the $C_{\min }$ levels were $3.2 \pm 2.9$ and $9.3 \pm 5.6 \mu \mathrm{g} / \mathrm{mL}$, respectively $(P=0.002)$. In only six $(40 \%)$ of the patients in the high-dose groups and none of the patients in the standard-dose group, amikacin $\mathrm{C}_{\max }$ reached the target levels $(>64 \mu \mathrm{g} / \mathrm{mL})$, whereas the amikacin mean $\mathrm{C}_{\min }$ levels in the high-dose group were above the threshold of toxicity $(5 \mu \mathrm{g} / \mathrm{mL})$.

Conclusion: Our results suggest that the optimum dose of amikacin should be determined for elderly critically ill patients. It seems that higher-than-standard doses of amikacin with more extended intervals might be more appropriate than standard once-daily dosing in the elderly critically ill patients.

Keywords: amikacin, elderly, high-dose, critical illness, pharmacokinetics, therapeutic drug monitoring

\section{Introduction}

Aminoglycosides are polar and low-protein binding antibiotics. They demonstrate interesting pharmacokinetic and pharmacodynamic characteristics, making them a valuable class of antibiotics in the treatment of invasive microorganisms. The emerging bacterial resistance and decline in microbiological susceptibility for aminoglycosides has not been developed extensively during the last decades, in comparison to other classes of antibiotics. ${ }^{1}$

In critically ill patients, the pharmacokinetic properties of aminoglycosides may differ. The most important change is the increase in the volume of distribution (VD) of polar drugs, which can lead to suboptimal dosing. ${ }^{2}$ The amount of increase in VD is 
related to the severity of illness, and the VD of aminoglycosides may be a predictor of capillary leakage that is derived from sepsis. ${ }^{3}$ The antibacterial activity of aminoglycosides is best related to plasma peak concentration $\left(\mathrm{C}_{\max }\right)$ and the ratio of $\mathrm{C}_{\text {max }}$ to minimum inhibitory concentration (MIC) for specific bacteria. It is suspected that a $\mathrm{C}_{\max } / \mathrm{MIC}$ ratio greater than eight is required for optimum bactericidal effects and can improve the patients' outcome, particularly if highly resistant bacteria are responsible for the infection. ${ }^{4}$ For serious infections and those caused by multidrug-resistant pathogens in an intensive care unit (ICU) setting, such as Pseudomonas aeruginosa and Enterobacteriaceae, the MIC clinical breakpoint is $8 \mu \mathrm{L} / \mathrm{mL}$ for amikacin. ${ }^{5}$ Thus, to achieve the target $\mathrm{C}_{\max } / \mathrm{MIC}$, reaching a $\mathrm{C}_{\max } \geq 64 \mu \mathrm{L} / \mathrm{mL}$ would be necessary.

An increase in VD can diminish the achievement of desirable $\mathrm{C}_{\max }$ with standard recommended doses in critically ill patients. It has been demonstrated that the administration of higher-than-standard doses of amikacin (ie, $25-30 \mathrm{mg} / \mathrm{kg}$ ) in critically ill patients might result in more patients achieving appropriate target peak levels without additional toxicity. ${ }^{6}$

Aging is associated with various physiological changes in the human body. These changes can alter the pharmacokinetic properties of prescribed drugs in the elderly. The most important changes that result in the alteration of pharmacokinetic properties are: reduction in renal capacity to eliminate drugs and changes in body water and fat content that can alter the drug's volume of distribution. ${ }^{7}$ A decrease in the VD of water-soluble drugs such as aminoglycosides in geriatric patients acts contrary to the increase in VD by sepsis and edema. This can cause the dosing of aminoglycosides to be more complex in this population.

The aim of this study was to evaluate the suitability of high-dose amikacin for critically ill elderly patients and to compare this to the standard $15 \mathrm{mg} / \mathrm{kg}$ dose in achieving desired peak levels and monitoring related trough levels for toxicity concerns.

\section{Patients and methods}

This was a prospective, randomized, multicenter study performed in three ICUs. Forty elderly (age $\geq 65$ years) patients with a documented or suspected severe gram-negative infection in whom amikacin treatment was indicated, and who have a normal serum creatinine $(\mathrm{SrCr})$ level $(\leq 1.2 \mathrm{mg} / \mathrm{dL})$, were consecutively enrolled in the study and randomly assigned to two treatment groups. Group A patients received $15 \mathrm{mg} / \mathrm{kg}$ amikacin once daily and Group B patients received $25 \mathrm{mg} / \mathrm{kg}$ amikacin once daily. Amikacin was infused over one hour in all cases. All the patients received other standard treatments and care based on staff decisions. Amikacin was administered for 7 days during the study period, and the physician made a continuation decision after 7 days, usually based on the culture results. All the patients were monitored for at least 10 days for changes in the renal function tests. The ethical committee of Tehran University of Medical Sciences and Health Services approved the study protocol. In all cases, a written informed consent form was obtained from the patient's closest relatives or guardian, which was accepted by the ethical committee. Amikacin was given in combination with a broad-spectrum $\beta$-lactam or carbapenem based on the local protocols. Patients were excluded from the study if they had any of the following conditions: dissatisfaction of patients or family, receiving an aminoglycoside in the last 2 weeks prior to the study, baseline creatinine clearance $(\mathrm{ClCr})$ $<40 \mathrm{~mL} / \mathrm{min}$, increase in $\mathrm{SrCr}$ by $0.3 \mathrm{mg} / \mathrm{dL}$ or more, need for amikacin dose adjustment for any reason, viral hepatitis, rise in hepatic aminotransferases to more than three times the normal upper limit, BMI $\geq 35 \mathrm{~kg} / \mathrm{m}^{2}$, severe heart failure (ejection fraction $<30 \%$ ), neoplastic disorders with a history of chemotherapy, neuromuscular disease, and a history of allergy to the aminoglycosides. Ideal body weight (IBW) was used to calculate the amikacin dose for every patient using the following formula: IBW $=50 \mathrm{~kg}$ (45 kg in women) $+2.3 \mathrm{~kg}$ for each inch over five feet. In patients whose body weight was over $30 \%$ of their IBW, the adjusted body weight (ABW) was used to calculate the amikacin doses: ${ }^{8}$

$\mathrm{ABW}=\mathrm{IBW}+0.4 *(\mathrm{TBW}-\mathrm{IBW})$

The blood samples of the patients were collected on baseline and on Days 3 and 7, after 1-hour infusion for measuring serum amikacin peak $\left(\mathrm{C}_{\max }\right)$ levels, and $30 \mathrm{~min}$ before the next dose for measuring the serum amikacin trough $\left(\mathrm{C}_{\min }\right)$ levels. The samples were collected in 5-mL plain tubes (without anticoagulant). After clots were completely formed (15-30 $\mathrm{min}$ ), all blood samples were centrifuged for $10 \mathrm{~min}$ in 3,000 rpm and then serum was separated. All samples were stored at $-70^{\circ} \mathrm{C}$ until analysis.

Demographic data, comorbidities, and admission diagnoses were recorded for all patients. Disease severity was characterized by the Acute Physiology and Chronic Health Evaluation II score. ${ }^{9}$ Positive microbiological cultures were recorded. Biological data, including coagulation parameters, complete blood count, electrolytes, urea, and creatinine were recorded at inclusion and daily thereafter. $\mathrm{ClCr}$ was estimated with the Cockcroft-Gault equation:

$$
\left(\mathrm{ClCr}=\frac{(140-\text { age }) * \mathrm{IBW}}{\mathrm{SrCr} * 72} \text { in women } \times 0.85\right)
$$


Renal dysfunction was diagnosed when $\mathrm{SrCr}$ was $>1.2 \mathrm{mg} / \mathrm{dL}$. Acute renal failure was defined by a rise in SrCr by $0.3 \mathrm{mg} / \mathrm{dL}$ or higher and/or urine output $<0.5 \mathrm{~mL} /$ $\mathrm{kg}$ per hour for more than 6 hours, based on AKIN criteria. ${ }^{10}$

The amikacin serum concentrations were quantified by fluorescence polarization immunoassay with the COBAS INTEGRA analyzer (Roche GmbH, D-68298 Mannheim).

Statistical analyses were performed using SPSS 16.0 (SPSS Inc., Chicago, IL, USA) for Windows. Descriptive statistics were computed for all study variables. A KolmogorovSmirnov test was used, and histograms and normal quantile plots were examined to verify the normality of distribution of continuous variables. Discrete variables were expressed as counts (percentage), and continuous variables as mean \pm SD. The demographic and clinical differences between study groups were assessed using $\chi^{2}$, Fisher's exact test, Student's $t$-test, or the Mann-Whitney $U$-test, as appropriate.

For every individual patient, the elimination constant was calculated using the following equation:

$$
\mathrm{K}=\frac{\ln \frac{\mathrm{C} 1}{\mathrm{C} 2}}{t 2-t 1}
$$

Amikacin half-life ( $\left.\mathrm{t}^{1} / 2\right), \mathrm{VD}$, and clearance $(\mathrm{Cl})$ for every patient was calculated using the following equations:

$$
\begin{gathered}
t \frac{1 / 2=\frac{0.693}{\mathrm{~K}}}{(\mathrm{~S})(\mathrm{F})(\text { Dose })} \\
\mathrm{Vd}=\frac{\frac{\mathrm{Css} 1}{\left(1-e^{-k \tau}\right)} e^{-k t 1}}{\mathrm{Cl}=\mathrm{K} \times \mathrm{Vd}}
\end{gathered}
$$

\section{Results}

Forty patients ( $\geq 65$ years) were enrolled in the study over a 14-month period. Seven patients were excluded from the study due to different reasons: Four patients died during the study period, two patients were excluded due to early discharge from ICU, and in one patient amikacin was discontinued on the second day because of the culture results. Finally, data from a total of 33 patients were analyzed: 18 patients in Group A received $15 \mathrm{mg} / \mathrm{kg}$ amikacin per day and 15 patients in Group B received $25 \mathrm{mg} / \mathrm{kg}$ amikacin per day. The mean age of the patients was 72.90 years, SD: \pm 7.7 . The results of the independent sample $t$-test revealed that there were no significant differences in age, sex, baseline $\mathrm{ClCr}$, initial Acute Physiology and Chronic Health Evaluation II score,
Table I The baseline parameters of the patients in Groups A and $B$

\begin{tabular}{llll}
\hline Patient's demographic & $\begin{array}{l}\text { Group A } \\
\text { (15 mg/kg) }\end{array}$ & $\begin{array}{l}\text { Group B } \\
\mathbf{( 2 5} \mathbf{~ m g / k g )}\end{array}$ & P-value \\
\hline Age (years) & $71.38 \pm 6.33$ & $74.73 \pm 9.1$ & 0.443 \\
Sex (men/total) & $12 / 18$ & $9 / 15$ & 0.357 \\
Baseline APACHE II score & $16.00 \pm 4.6$ & $16.26 \pm 4.43$ & 0.965 \\
Baseline Cr (mL/min) & $65.43 \pm 20.15$ & $56.09 \pm 12.94$ & 0.187 \\
IBW (kg) & $60.72 \pm 11.48$ & $56.53 \pm 8.32$ & 0.279 \\
\hline
\end{tabular}

Note: Data is presented as mean \pm SD, except for sex.

Abbreviations: APACHE, Acute Physiology and Chronic Health Evaluation; $\mathrm{CrCl}$, creatinine clearance; IBW, ideal body weight.

and IBW between two treatment groups. Table 1 shows the baseline parameters as well as the SD of the mean amounts and the $P$-value of differences in Groups A and B.

Seven patients ( $21 \%$ of the total) had positive blood cultures: one for Escherichia coli, one for P. aeruginosa, one for Acinetobacter baumannii, three for Klebsiella spp., and one with mixed Klebsiella and A. baumannii.

The mean amikacin dose in Group A and B patients was $927 \mathrm{mg}$, SD: \pm 180 (range: $600-1,250 \mathrm{mg}$ ), and 1,423 mg, SD: \pm 277 (range: $1,000-1,750 \mathrm{mg}$ ) respectively. The average $\mathrm{C}_{\max }$ on Day 3 in Group A patients with $15 \mathrm{mg} / \mathrm{kg} / \mathrm{d}$ amikacin was $30.41 \mu \mathrm{g} / \mathrm{mL}$, SD: \pm 11.09 (range: $16.72-56.64$ ) and average $\mathrm{C}_{\min }$ was $3.26 \mu \mathrm{g} / \mathrm{mL}$, SD: \pm 2.13 (range: $<0.3-8.7$ ). In Group B, the average $\mathrm{C}_{\max }$ on Day 3 was $52.28 \mu \mathrm{g} / \mathrm{mL}$, SD: \pm 16.11 (range: $23.86-70.28$ ) and the average $C_{\min }$ was $5.22 \mu \mathrm{g} / \mathrm{mL}, \mathrm{SD}: \pm 2.87$ (range: $<0.3-11.4$ ). On Day 7 of therapy, the average $\mathrm{C}_{\max }$ in Group A was $33.05 \mu \mathrm{g} / \mathrm{mL}$, SD: \pm 7.31 (range: $22.18-50.02$ ) and the average $\mathrm{C}_{\min }$ was 3.20 $\mu \mathrm{g} / \mathrm{mL}, \mathrm{SD}: \pm 2.92$ (range: $<0.3-9.9$ ). In Group B, the average $\mathrm{C}_{\max }$ on Day 7 was $60.01 \mu \mathrm{g} / \mathrm{mL}, \mathrm{SD}: \pm 17.64$ (range: $37.79-81.53)$ and the average $C_{\min }$ was $9.28 \mu \mathrm{g} / \mathrm{mL}$, SD: \pm 5.62 (range 2-20.4). There was no significant difference between $\mathrm{C}_{\max }$ and $\mathrm{C}_{\min }$ of Day 3 and Day 7 in the patients in low-dose group (Group A), but in the high-dose group (Group B) the $\mathrm{C}_{\min }$ of amikacin on Day 7 was significantly higher than on Day $3(P=0.012)$ although the peak levels were not different.

The average amikacin VD on Day 3 in Group A was 0.54 L/kg, SD: \pm 0.19 (range: $0.25-1.06$ ) and on Day 7 was 0.45 L/kg, SD: \pm 0.09 (range: $0.33-0.63),(P=0.279)$. In Group B, the average VD on Day 3 was $0.53 \mathrm{~L} / \mathrm{kg}$, SD: \pm 0.25 (range: $0.31-1.21$ ) and on Day 7 was $0.49 \mathrm{~L} / \mathrm{kg}$, SD: \pm 0.18 (range: $0.31-0.85)$. The mean pharmacokinetic parameters of amikacin in both groups are shown in Table 2.

When considering all the patients in both groups, there were no significant differences between VD of Day 3 and Day $7(P=0.14)$. Changes in VD during Days $3-7$ was also 
compared between each group, and again there were no significant differences (for Group A: $P=0.125$, for Group B: $P=0.731$ ).

As a primary outcome, no patient in Group A and only $40 \%$ of the patients in Group B attained target peak levels $\left(\mathrm{C}_{\max }>64 \mu \mathrm{g} / \mathrm{mL}\right)$ for killing the resistant pathogens. On the other hand, five patients in Group A (27.8\%) and 13 patients $(86.7 \%)$ in Group B had at least one trough level above $5 \mu \mathrm{g} / \mathrm{mL}$. No patient in Group A and six patients (40\%) in Group B had at least one trough level above $10 \mu \mathrm{g} / \mathrm{mL}$.

The $\mathrm{ClCr}$ of the patients in Groups A and B was calculated using the Cockcroft-Gault formula. The mean values of $\mathrm{ClCr}$ for each group on Days $0,3,5,7$, and 10 of the study are shown in Table 3 . The average $\mathrm{ClCr}$ of patients in each group was compared point-by-point using a $t$-test. Analysis showed that there were no significant differences between the $\mathrm{ClCr}$ of the baseline and the $\mathrm{ClCr}$ of Days 3, 5, and 7 in both groups and the $\mathrm{ClCr}$ of Day 10 in Group A. However, in Group B, $\mathrm{ClCr}$ was significantly reduced in comparison with the baseline on Day $10(P=0.016)$.

Although there was no statistically significant difference in the baseline $\mathrm{ClCr}$ between the two groups, when comparing the mean differences between the groups, $\mathrm{ClCr}$ was significantly lower in the high-dose group on Day $3(P=0.037)$, Day $7(P=0.049)$, and Day $10(P=0.004)$.

A repeated-measure analysis of $\mathrm{ClCr}$ also revealed that there was a significant difference in trend of $\mathrm{ClCr}$ between

Table 2 Mean pharmacokinetic parameters of amikacin in Groups A and B

\begin{tabular}{|c|c|c|c|}
\hline Values (mean \pm SD) & $\begin{array}{l}\text { Group A } \\
(15 \mathrm{mg} / \mathrm{kg})\end{array}$ & $\begin{array}{l}\text { Group B } \\
(25 \mathrm{mg} / \mathrm{kg})\end{array}$ & $P$-value \\
\hline VD Day 3 (L/kg) & $0.54 \pm 0.19$ & $0.53 \pm 0.25$ & 0.279 \\
\hline VD Day 7 (L/kg) & $0.45 \pm 0.09$ & $0.49 \pm 0.18$ & 0.549 \\
\hline Amikacin dose (mg/d) & $927 \pm 180$ & $1423 \pm 277$ & 0.000 \\
\hline$C_{\min }$ Day $3(\mu \mathrm{g} / \mathrm{mL})$ & $3.26 \pm 2.13$ & $5.22 \pm 2.87$ & 0.035 \\
\hline$C_{\max }$ Day $3(\mu \mathrm{g} / \mathrm{mL})$ & $30.4 I \pm 11.09$ & $52.28 \pm 16.11$ & 0.000 \\
\hline $\mathrm{C}_{\min }$ Day $7(\mu \mathrm{g} / \mathrm{mL})$ & $3.20 \pm 2.92$ & $9.28 \pm 5.62$ & 0.002 \\
\hline$C_{\max }$ Day $7(\mu \mathrm{g} / \mathrm{mL})$ & $33.05 \pm 7.31$ & $60.01 \pm 17.64$ & 0.001 \\
\hline$t^{1} / 2$ Day 3 (hour) & $7.11 \pm 2.46$ & $5.5 \mathrm{I} \pm 0.84$ & 0.568 \\
\hline t'1/2 Day 7 (hour) & $6.55 \pm 2.46$ & $9.04 \pm 2.60$ & 0.018 \\
\hline $\mathrm{Cl}$ amikacin Day $3(\mathrm{~mL} / \mathrm{min})$ & $55 \pm 35$ & $56 \pm 22$ & 0.91 \\
\hline $\mathrm{Cl}$ amikacin Day 7 (mL/min) & $51 \pm 32$ & $47 \pm 26$ & 0.72 \\
\hline
\end{tabular}

Abbreviations: $\mathrm{Cl}$, clearance; $\mathrm{t}^{1} / 2$, half-life; $\mathrm{VD}$, volume of distribution. two groups and in Group B, and that the trend was decreasing $(P=0.038)$.

Amikacin clearance was calculated for every patient using individual elimination constant and VD on Days 3 and 7. $\mathrm{ClCr}$ and amikacin clearance did not significantly change in Group A during Days 3-7, but in Group B, although $\mathrm{ClCr}$ did not change significantly, amikacin clearance reduced significantly from Days 3 to $7(P=0.048)$. As presented in Table 2, amikacin $\mathrm{t}^{1} 1 / 2$ and, consequently, its trough concentrations increased on Day 7 compared to Day 3 in the high-dose group.

The Pearson correlation test showed a weak but significant correlation between amikacin clearance on Day 7 and $\mathrm{ClCr}$ on Day $10(P=0.031, r=0.46)$.

None of the patients in either Group A or B developed kidney injury based on the AKIN criteria during the study period.

\section{Discussion}

Although the standard amikacin dosage is $15 \mathrm{mg} / \mathrm{kg} / \mathrm{d}$ in most references, ${ }^{11,12}$ it is shown that higher than this standard dose (ie, $25-30 \mathrm{mg} / \mathrm{kg}$ ) is necessary in critically ill patients to achieve the target $\mathrm{C}_{\max } / \mathrm{MIC}$ value of higher than 8-10 for more resistant bacteria in ICU settings. ${ }^{6,13}$

Presently, to the best of our knowledge, our study is the first that tested the success of high-dose, once-daily amikacin for achievement of target serum level, in the elderly population.

It is shown that the peak amikacin level $<40 \mu \mathrm{g} / \mathrm{mL}$ is associated with worse outcomes. ${ }^{14}$ In our study, almost all the patients who received standard doses of amikacin $(15 \mathrm{mg} /$ $\mathrm{kg} / \mathrm{d}$ ) had peak levels $<40 \mu \mathrm{g} / \mathrm{mL}$ in one or both of the two measuring days. Even when the amikacin trough exceeded the threshold of toxicity $(>5 \mu \mathrm{g} / \mathrm{mL}),{ }^{15}$ in four $(27 \%)$ patients of this group, the peak drug concentrations remained at $<40$ $\mu \mathrm{g} / \mathrm{mL}$. This is not surprising because the VD in critically ill patients increased largely in comparison to the normal population. In noncritically ill adult patients, the aminoglycoside VD is $0.25 \mathrm{~L} / \mathrm{kg},{ }^{16}$ but the mean VD in our patients was 0.54 and $0.46 \mathrm{~L} / \mathrm{kg}$ on Days 3 and 7, respectively. Some studies reported a mean value of $0.4-0.45 \mathrm{~L} / \mathrm{kg}$ for VD of aminoglycosides in critically ill adult patients. ${ }^{13,17}$ Fernández de Gatta et $\mathrm{al}^{18}$ reported a mean value of $0.52 \pm 0.21 \mathrm{~L} / \mathrm{kg}$ for

Table 3 Mean values for $\mathrm{CrCl}$ in Groups A and B

\begin{tabular}{llllll}
\hline Groups (mL/min) & CICr base & CICr Day 3 & CICr Day 5 & CICr Day 7 & CICr Day I0 \\
\hline Group A (15 mg/kg) & $65 \pm 20$ & $68 \pm 21$ & $65 \pm 27$ & $67 \pm 23$ & $72 \pm 26$ \\
Group B (25 mg/kg) & $56 \pm 12$ & $54 \pm 14$ & $53 \pm 15$ & $53 \pm 14$ & $47 \pm 10$ \\
\hline
\end{tabular}

Abbreviation: $\mathrm{ClCr}$, clearance of creatinine. 
the VD of amikacin in critically ill patients. This is in line with our study, but their patient's mean age was 50 years while all of our patients were $\geq 65$ years and with a mean age of 73 years. We know that aging is associated with an increase in body fat and a decrease in lean body mass and total body water; these changes will affect the apparent VD of drugs, and in the case of polar drugs VD will be decreased. ${ }^{19}$ Surprisingly, we found that in our elderly patients, the VD of amikacin increased to at least as high amount as previously reported for younger adult critically ill patients. However, variations of VD in our patients were very high $(0.25-1.2 \mathrm{~L} /$ $\mathrm{kg}$ ), which emphasizes the great importance of therapeutic drug monitoring in geriatric critically ill patients.

In the study of Gálvez et al, ${ }^{6}$ only $39 \%$ of patients with $25 \mathrm{mg} / \mathrm{kg}$ and $76 \%$ with $30 \mathrm{mg} / \mathrm{kg}$ of amikacin reached peak amikacin levels $>60 \mu \mathrm{g} / \mathrm{mL}$. White et $\mathrm{al}^{20}$ in a retrospective investigation reported that with a higher than approved dose for amikacin (ie, $>15 \mathrm{mg} / \mathrm{kg} / \mathrm{d}$ ), only $63.0 \%$ and $36.9 \%$ of patients in their institution reached the target $\mathrm{Cmax} / \mathrm{MIC}$ of $\geq 10$ and $\mathrm{AUC}_{24} / \mathrm{MIC}$ of $\geq 75$ respectively, but only $45.3 \%$ of their patients were critically ill. ${ }^{20}$ Our study revealed that with standard doses of amikacin (ie, $15 \mathrm{mg} / \mathrm{kg} / \mathrm{d}$ ), no patient reached target peak levels. Even in the high-dose group, in less than half of the patients did the amikacin peak concentrations reach the target level $(>64 \mu \mathrm{g} / \mathrm{mL})$.

As shown in Table 2, elimination $t^{1 / 2}$ is increased in our elderly critically ill patients compared to the $t^{1} / 2$ of $2-3$ hours in the normal adult population. This is partly due to the preexisting renal dysfunction due to aging, although other factors such as critical illness, decreased renal flow due to hypo-perfusion, etc., could also play a role.

There are some limitations which should be addressed in this study. The sample size is relatively small, but considering the difficulty of patient enrollment based on the inclusion and exclusion criteria and because the primary objective was to show the efficiency of two dose regimen of amikacin to achieve desired level and not a statistical comparison of a clinical outcome, the results might be less influenced by the sample size. Another limitation which could be mentioned is the $\mathrm{ClCr}$ estimation by the CockcroftGault equation. This equation may overestimate $\mathrm{ClCr}$ in the elderly population because of reduced lean body mass by aging. Measuring $\mathrm{ClCr}$ by the method of 24-hour urine collection is the gold standard method. Also, we acknowledge that more frequent sampling during a 24-hour period would offer a more precise calculation of some pharmacokinetic parameters such as VD compared to a peak and trough level measurement.

\section{Conclusion}

It might prove reasonable to administer amikacin in high doses (at least $25 \mathrm{mg} / \mathrm{kg}$ ) in elderly critically ill patients to achieve target peak levels ( $>64 \mu \mathrm{g} / \mathrm{mL}$ ). Nevertheless, to reduce toxicity, the kidneys should be allowed more time to eliminate the drug. This interval in the elderly people should be more than 24 hours (based on the renal functional reserve). It should be noted that due to the great variability in the VD between patients and rapid changes in critical illness, the true interval cannot be predicted unless the drug level is measured at appropriate times and individualized treatment is available for every patient.

\section{Disclosure}

The authors report no conflicts of interest in this work.

\section{References}

1. Leibovici L, Vidal L, Paul M. Aminoglycoside drugs in clinical practice: an evidence-based approach. J Antimicrob Chemother. 2009;63(2):246-251.

2. Scaglione F, Paraboni L. Pharmacokinetics/pharmacodynamics of antibacterials in the Intensive Care Unit: setting appropriate dosing regimens. Int J Antimicrob Agents. 2008;32(4):294-301.

3. Marik PE. Aminoglycoside volume of distribution and illness severity in critically ill septic patients. Anaesth Intensive Care. 1993;21(2):172-173.

4. Moore RD, Lietman PS, Smith CR. Clinical response to aminoglycoside therapy: importance of the ratio of peak concentration to minimal inhibitory concentration. J Infect Dis. 1987;155(1):93-99.

5. Aminoglycosides: EUCAST clinical MIC breakpoints. Available from: http://www.eucast.org/clinical_breakpoints/.

6. Galvez R, Luengo C, Cornejo R, et al. Higher than recommended amikacin loading doses achieve pharmacokinetic targets without associated toxicity. Int J Antimicrob Agents. 2011;38(2):146-151.

7. Turnheim K. Drug therapy in the elderly. Exp Gerontol. 2004;39(11-12): 1731-1738.

8. Traynor AM, Nafziger AN, Bertino JS Jr. Aminoglycoside dosing weight correction factors for patients of various body sizes. Antimicrob Agents Chemother. 1995;39(2):545-548.

9. Knaus WA, Draper EA, Wagner DP, Zimmerman JE. APACHE II: a severity of disease classification system. Crit Care Med. 1985;13(10):818-829.

10. Mehta RL, Kellum JA, Shah SV, et al. Acute Kidney Injury Network: report of an initiative to improve outcomes in acute kidney injury. Crit Care. 2007;11(2):R31

11. Chambers HF. The aminoglycosides. In: Brunton LL, editor. Goodman and Gilman's the Pharmacological Basis of Therapeutics. Vol 2, 11th ed. New York: McgGraw-Hill; 2006:1155-1171.

12. Gilbert DN, Leggett JE. Aminoglycosides. In: Mandell GL, Bennett JE, Dolin R, editor. Mandell, Douglas, and Bennett's Principles and Practice of Infectious Diseases. 7 ed. Philadelphia: Churchill Livingstone; 2010:359-384.

13. Taccone FS, Laterre PF, Spapen H, et al. Revisiting the loading dose of amikacin for patients with severe sepsis and septic shock. Crit Care. 2010;14(2):R53.

14. Moore RD, Smith CR, Lietman PS. Association of aminoglycoside plasma levels with therapeutic outcome in gram-negative pneumonia. Am J Med. 1984;77(4):657-662.

15. Tod M, Lortholary O, Seytre D, et al. Population pharmacokinetic study of amikacin administered once or twice daily to febrile, severely neutropenic adults. Antimicrob Agents Chemother. 1998;42(4):849-856. 
16. Bauer LA. Applied clinical pharmacokinetics. Vol 2, 2nd ed. New York: McGraw Hill Medical; 2008.

17. Triginer C, Izquierdo I, Fernandez R, et al. Gentamicin volume of distribution in critically ill septic patients. Intensive Care Med. 1990;16(5): 303-306.

18. Fernandez de Gatta MM, Mendez ME, Romano S, Calvo MV, Dominguez-Gil A, Lanao JM. Pharmacokinetics of amikacin in intensive care unit patients. J Clin Pharm Ther. 1996;21(6):417-421.
19. Schenker S. The aging liver. In: Abrams WB, Beers MH, Berkow R, Fletcher AJ, Besdine RW, editors. The Merck Manual of Geriatrics. 2nd ed. Whitehouse Station, NJ: Merck Research Laboratories Whitehouse Station; 1995:696-699.

20. White BP, Lomaestro B, Pai MP. Optimizing the initial amikacin dosage in adults. Antimicrob Agents Chemother. 2015;59(11): 7094-7096.

\section{Publish your work in this journal}

Infection and Drug Resistance is an international, peer-reviewed openaccess journal that focuses on the optimal treatment of infection (bacterial, fungal and viral) and the development and institution of preventive strategies to minimize the development and spread of resistance. The journal is specifically concerned with the epidemiology of antibiotic resistance and the mechanisms of resistance development and diffusion in both hospitals and the community. The manuscript management system is completely online and includes a very quick and fair peerreview system, which is all easy to use. Visit http://www.dovepress.com/ testimonials.php to read real quotes from published authors. 